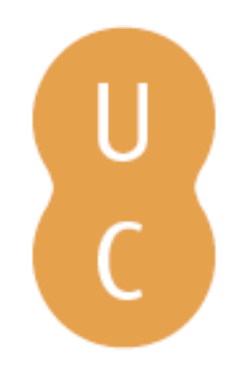

\title{
pompalina
}

\section{O papel da música no teatro de Gil Vicente}
Autor(es):
Camões, José
Publicado por: Imprensa da Universidade de Coimbra
URL persistente:
URI:http://hdl.handle.net/10316.2/47479
DOI:
DOl:https://doi.org/10.14195/978-989-26-1548-6_17

Accessed : $\quad$ 26-Apr-2023 09:29:09

A navegação consulta e descarregamento dos títulos inseridos nas Bibliotecas Digitais UC Digitalis, UC Pombalina e UC Impactum, pressupõem a aceitação plena e sem reservas dos Termos e Condições de Uso destas Bibliotecas Digitais, disponíveis em https://digitalis.uc.pt/pt-pt/termos.

Conforme exposto nos referidos Termos e Condições de Uso, o descarregamento de títulos de acesso restrito requer uma licença válida de autorização devendo o utilizador aceder ao(s) documento(s) a partir de um endereço de IP da instituição detentora da supramencionada licença.

Ao utilizador é apenas permitido o descarregamento para uso pessoal, pelo que o emprego do(s) título(s) descarregado(s) para outro fim, designadamente comercial, carece de autorização do respetivo autor ou editor da obra.

Na medida em que todas as obras da UC Digitalis se encontram protegidas pelo Código do Direito de Autor e Direitos Conexos e demais legislação aplicável, toda a cópia, parcial ou total, deste documento, nos casos em que é legalmente admitida, deverá conter ou fazer-se acompanhar por este aviso.

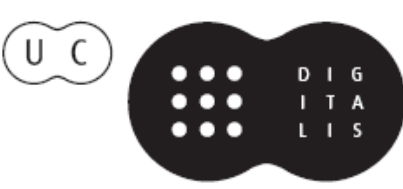



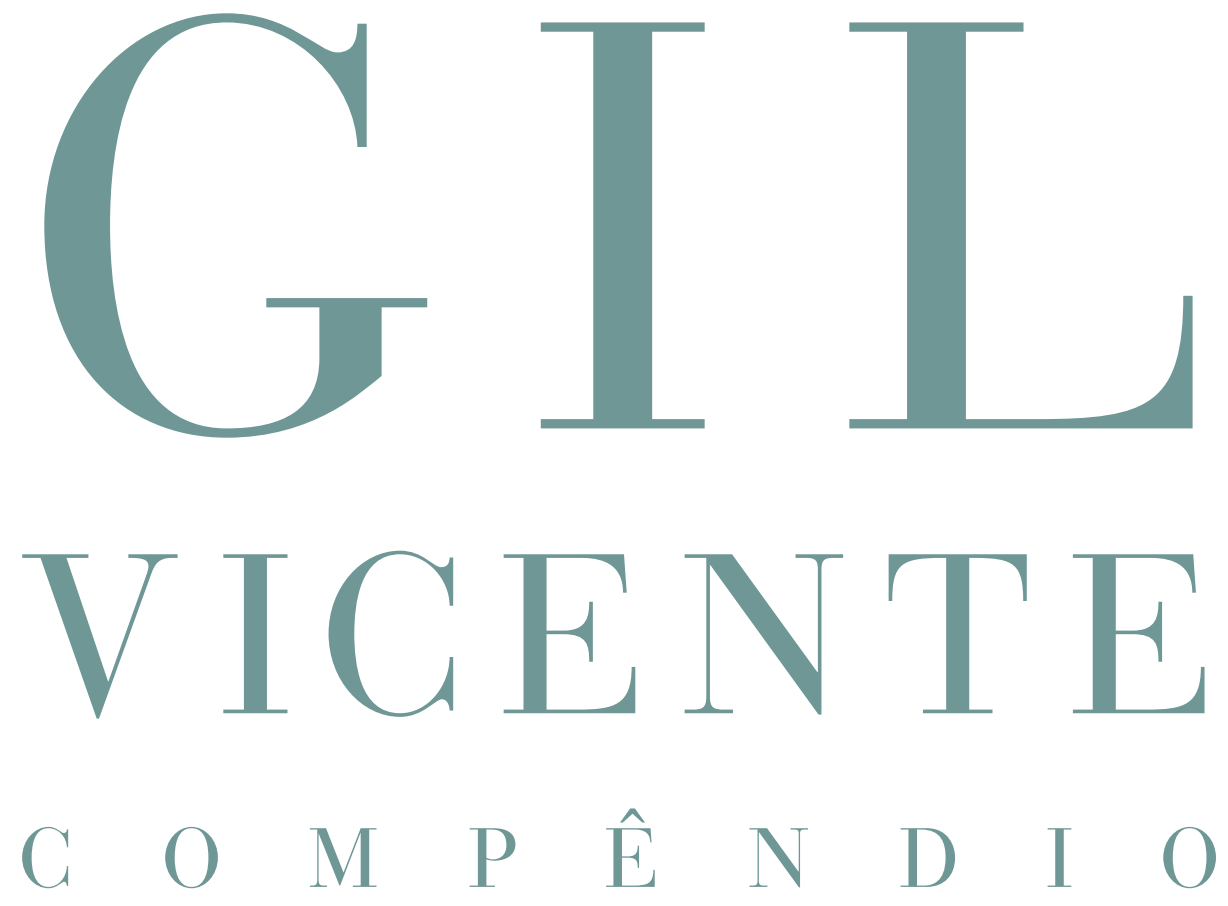

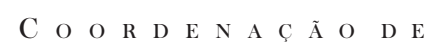

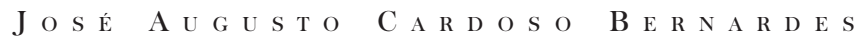

E J O S É C A M Õ E S

CoimbraCompanions

IVPRENSA DA UNIVERSIDADE DE COIMBRA

COIMBRA UNIVERSITY PRESS

IMPRENSA NACIONAL 
XVII

\title{
O papel da música no teatro de Gil Vicente
}

\author{
José Camões
}

Centro de Estudos de Teatro

UNIVERSIDADE DE LISBOA 
(Página deixada propositadamente em branco) 
Nas manifestações teatrais portuguesas mais antigas que se encontram documentadas, a música surge como elemento integrante em diversos níveis. Ocorre, por exemplo, como número de programa paralelo - lembremos a mourisca retorta executada em 1490 na cidade de Évora por ocasião das festas do casamento do príncipe D. Afonso, filho de D. João II, com a princesa D. Isabel, filha dos reis católicos. Esse momento musical foi registado por alguns cronistas, entre os quais Garcia de Resende que, no capítulo 123 da sua Vida e feitos del rei D. João II (1545: 74c-75c), o descreve:

E houve aí ũa muito grande representaçam dum rei de Guiné em que vinham três gigantes espantosos que pareciam vivos, de mais de quarenta palmos cada um, com ricos vestidos, todos pintados d'ouro que parecia cousa muito rica, e com eles ũa mui grande e rica mourisca retorta em que vinham dozentos homens tintos de negro, muito grandes bailadores, todos cheos de grossas manilhas polos braços e pernas, douradas, que cuidavam que eram d'ouro e cheos de cascavês dourados e muito bem concertados, cousa mui bem feita e de muito custo por serem tantos, em que se gastou muita seda e ouro, e faziam tamanho roído com os muitos cascavês que traziam que se nam ouviam com eles.

O ruído que os cascavéis e manilhas produziram não terá deixado ouvir as palavras que cantavam ou até as da leitura do breve que o rei da Guiné ofereceu à princesa, escrito pelo coudel-mor Francisco da Silveira, copiadas 
também por Garcia de Resende, desta vez no Cancioneiro Geral de 1516 (f. 23b). Creio que se trata de um dos registos mais antigos das palavras proferidas em espetáculo de teatro em Portugal e seguramente o mais antigo da convenção de língua de negro criada para o teatro:

\begin{abstract}
A mim rei de negro estar Serra Lioa
longe muito terra onde viver nós

lodar caitbela tubao de Lisboa

falar muao novas calar pera vós.

Querer a mim logo ver vós como vai

leixar molher meu partir muito sinha

porque sempre nós servir vosso pai

folgar muito negro estar vós rainha.
\end{abstract}

Aqueste gente meu taibo terra nossa

nunca folgar andar sempre guerra

nam saber qui que balhar terra vossa

balhar que saber como nossa terra.

Se logo vós quer mandar a mim venha

fazer que saber tomar que achar

mandar fazer taibo lugar Des mantenha

e logo meu negro senhora balhar.

O acompanhamento por música das ações e das palavras no teatro é mecanismo de que o espetáculo teatral não prescindirá nos séculos seguintes. Gil Vicente irá incluí-lo nas suas obras de modos variados e imporá também uma nova função da música no teatro, memória talvez do que acontecia nos serões: o remate do espetáculo. Nas suas produções, o teatro, e até talvez o serão em que se representa, termina quase sempre com música, anúncio de fim de festa. Das 45 ações teatrais que se conhecem, concebidas por Gil Vicente, em apenas 9 não existe menção explícita de concluírem com música instrumental, canto ou dança. O paradigma é o da Comédia sobre a devisa da cidade de Coimbra: "E assi fenece esta comédia, saindo-se com sua música», sem, no entanto, haver indicação de instrumentos, mas com aparato musical 
que se adivinha de monta, como acontece, também, no auto ou na farsa da Fama: "Aqui coroam as Virtudes a Fama e a põem em seu carro triunfal com música e assi a levam e se acaba esta susodita farsa."

A história da cultura dá a Gil Vicente o lugar de autor literário, dramaturgo, encenador e ator. Ficam ainda por mencionar outros talentos que possuía, e que, de momento, só podem ser encontrados no interior da própria obra, entre eles o de músico. No final do Auto da Sebila Cassandra, representado a D. Leonor no Mosteiro da Madre de Deus, em Xabregas, uma peça de devoção que termina com a adoração do presépio, em oração, as personagens pastoris das sibilas e dos profetas bíblicos cantam uma cantiga que, segundo a didascália, foi «feita e ensoada polo autor». Pela rubrica seguinte, sabemos que para além de ter sido cantada foi também dançada, seguindo-se-lhe ainda um vilancete, talvez também ele cantado e dançado. E sabemos, sobretudo, que a música foi composta pelo próprio Gil Vicente. No Breve Sumário da História de Deus regista-se um romance que «fez o mesmo autor ao mesmo propósito». O verbo fazer refere claramente a composição poética, mas pode ser que indique também uma nova toada ou melodia ao som da qual era cantada, salvaguardando a possibilidade de ter sido executada com melodia alheia já existente, como era prática comum.

As didascálias deixam bem entender que é esse o programa do teatro: finalizar com música; mas a informação é bastante escassa e genérica. Por vezes adianta-se um pouco e explicita-se o género de composição ou de baile com que se dá fim ao teatro: chacota, folia, canto de terreiro, três por três ou uma suíça. Normalmente, o final é pautado com o entoar e o bailar de uma cantiga ou de um vilancete, nas peças de cariz profano, como farsas ou comédias, ou com um qualquer cântico religioso nas obras de devoção. No entanto, esta aparente sistematização nem sempre se aplica com um rigor absoluto, bastando atentar no caso do Auto da Fé - uma explicação do significado da liturgia — que termina com uma forma poética de "ensalada», que desta vez até "veio de França», aparentemente imprópria de uma manifestação religiosa.

Contudo, nota-se que, com alguma frequência, há uma tentativa de ajustar a música à ocasião em que se representa ou que se representa. A cantiga que 
dá fim à farsa do Juiz da Beira é adequada à naturalidade do protagonista, que se deslocou da província à corte, em Lisboa, e elogia as serranas beirãs a par das virtudes da serra da Estrela ${ }^{1}$.

Fim da farsa do Juiz da Beira. Sairam-se todos cantando a cantiga seguinte:

Vamos ver as sintrãs, 891

senhores, à nossa terra, que o milhor está na serra.

As serranas coimbrãs

e as da serra da Estrela

por mais que ninguém se vela

valem mais que as cidadãs.

São pastoras tam louçãs

que a todos fazem guerra

bem desd'o cume da serra.

Ainda na mesma ordem de criação de referente reconhecível é o contraste entre harmonia e desarmonia com que os dois destinos das almas são sonoramente convocados, no final de Purgatório, na "cantiga muito desacordada" com que os diabos levam o Taful e no canto dos Anjos que transportam o Menino: «Saem-se os Diabos do batel e com ũa cantiga muito desacordada levam o Taful. E os Anjos cantando levam o Menino e fenece esta segunda cena.» Muito a propósito, a tragicomédia da Exortação da Guerra, que insta o público a contribuir com donativos avultados para uma expedição militar ao Norte de África, termina com uma marcha militar que organiza uma coreografia em caracol. Não se sabe se houve música instrumental a acompanhar o canto e a dança, mas a verdade é que nos versos se prevê uma qualquer melodia indicada com «Ta la la la lão ta la la la lão", numa espécie de contraponto ao recitado/declamado, num esquema que se repete por três estrofes.

1 Cita-se por As Obras de Gil Vicente, dir. José Camões, Lisboa, Centro de Estudos de Teatro/Imprensa Nacional-Casa da Moeda, 2002. 
Todas estas figuras se ordenaram em caracol, e as vozes cantaram e representaram o que se segue cantando todos:

Ta la la la lão ta la la la lão.

ANIBAL Avante avante senhores

que na guerra com razão

anda Deos por capitão.

CAntam Ta la la la lão ta la la la lão.

Quase epítome desta adequação a uma verosimilhança absoluta é o final da tragicomédia Nau de Amores, que termina com a partida da nau simbólica de Lisboa, encenada com os mesmos preparativos com que da Ribeira zarpavam as naus da carreira da Índia, havendo o cuidado de indicar minuciosamente o modo como cada personagem deveria cantar:

Começaram a cantar a prosa que comummente cantam nas naus à salve, que diz: Bom Jesu nosso senhor, tem por bem de nos salvar etc. O Velho cantava coma velho, o Negro após ele coma negro, e respondiam-lhe os passageiros a quatro vozes de canto d'órgão. E com isto se vão com a Nau e fenece esta tragicomédia.

A polifonia é um modo a que Gil Vicente recorre mais de uma vez. A já referida ensalada que veio de França para o Auto da Fé é cantada a quatro vozes, os Cavaleiros que se apressam para o Paraíso na Barca do Inferno "vêm cantando a quatro vozes», na tragicomédia das Cortes de Júpiter há um romance que "Os Planetas e signos cantam a quatro vozes pera com as palavras dele e música desencantarem a moura Tais de seu encantamento».

Na Tragicomédia Pastoril da Serra da Estrela, o "canto de órgão" não parece ajustado ao que se representa e a rubrica nota-o: «Ordenaram-se todos estes pastores em chacota como lá [na Beira] se costuma, porém a cantiga dela foi cantada de canto d'órgão.» Todavia, poderá ter sido invenção adequada ao espaço e à festa em que o teatro se apresenta.

A cantiga executada é um vilancete que retoma aspetos formais e temáticos das antigas cantigas de amigo: 
Nam me firais madre

que eu direi a verdade.

Madre um escudeiro

da nossa rainha

falou-me d'amores

vereis que dezia

eu direi a verdade.

Falou-me d'amores

vereis que dezia

quem te me tivesse

desnuda em camisa

eu direi a verdade.

Ocasiões há em que o final da função teatral é executado com maior estrondo pomposo, de grande efeito espetacular, adequado à solenidade do narrado ou do celebrado. É o que acontece no final do Breve Sumário da História de Deus, em que a aparição do Cristo da Ressurreição se faz ao som de trombetas e charamelas.

Contribui para este aparatoso final o Diálogo de uns Judeus, agora também eles contaminados pelo regozijo que o tempo da ressurreição propicia, numa espécie de convite à festa comunitária (é bem possível que os versos se dirijam também aos espectadores e não apenas às figuras do auto):

Chacota na mão, fender os ouvidos

a quem nos ouvir. Alto, começar

a travar dos vestidos e cabecear.

Caso único parece-me ser o do Auto de Mofina Mendes em que o número musical final tem as partes bem distribuídas pelos diversos executantes: os anjos tocam os instrumentos, as Virtudes cantam e os pastores bailam.

Esta rubrica aponta para a existência de uma especialização dos intérpretes, o que nem sempre acontece nos demais textos de Gil Vicente, em que o 
desempenho de uma personagem exige talentos diversos por parte do ator, como voz afinada para o canto e até competência para tocar algum instrumento musical, normalmente a viola no ambiente urbano e gaita ou um instrumento de sopro no mundo rústico. As representações contam, muitas vezes, com cantores que entram exclusivamente no número final. No Breve Sumário da História de Deus há a menção explícita à entrada dos cantores que «trazem ũa tumba onde vem ũa devota imagem de Cristo morto»; o remate festivo da Comédia do Viúvo requer também a atuação de quatro cantores que andam «um compasso ao som de uma cantiga»; no Auto dos Físicos entram "quatro cantores que cantam a vozes uma ensalada"; e em Amadis de Gaula e em Dom Duardos, têm papel atribuído umas «donzelas músicas».

Aliás, Gil Vicente conhece bem a gama de cantores e, no seu teatro, brinca com os cantores da corte:

$$
\begin{aligned}
& \text { SoL Irão todolos cantores } \\
& \text { contrasaltas, carapaus } \\
& \text { os tiples, alcapetores } \\
& \text { enxarrocos, os tenores } \\
& \text { contrabaxas, bacalhaus. } \\
& \text { (Cortes de Júpiter) }
\end{aligned}
$$$$
252
$$

O hábito, talvez normativo, de terminar o teatro com alguma forma de canto deveria estar de tal modo enraizado na expectativa do público que o efeito de surpresa por omissão é matéria do remate da farsa do Clérigo da Beira:

E ao que quereis saber 906

das damas e amadores

o domingo que vier

eu direi quanto souber

delas e seus servidores.

Insinar-vos-ei então

cantigas com que folgueis

e agora nam canteis 
fique por concrusão

que esse dia cantareis.

Seria por falta de tempo? Por falta de cantores? A verdade é que este é um dos exemplos evidentes em que a ausência de música final parece ter estado programada. Pelo menos houve a necessidade de explicá-la e, até, de desculpá-la.

Mas a música no teatro de Gil Vicente está longe de ser confinada ao papel de um elemento de remate. Muitas das peças integram a execução musical ao longo do espetáculo, se bem que de forma ligeiramente diferente entre si.

Casos há em que a música é quase constante durante a representação. Acontece na Farsa da Lusitânia, e de formas variadas. Esta farsa comporta dois momentos distintos: uma espécie de prólogo que encena o dia-a-dia de uma família judaica e a encenação da origem mitológica de Portugal. No prólogo, Gil Vicente utiliza a música como meio de definir traços característicos das personagens: pai e filho, alfaiates, acompanham a costura entoando um romance que conta as aventuras do Cid Campeador na conquista da cidade de Valença aos mouros — "Ai Valença guai Valença» — ao passo que a mãe tem uma predileção especial por cantigas de tema amoroso, entoando uma verdadeira cantiga de amigo de sabor medieval, já um pouco em desuso no tempo de Gil Vicente - "Donde vindes filha, branca e colorida?" - o que provoca o desabafo próprio da masculinidade:

Se a cantiga nam falar

em guerra de coitiladas

e d'espadas desnuadas

lançadas e encontradas

e coisas de peleijar

nam nas quero ver cantar

nem as posso oivir cantadas.

Na segunda parte da farsa, a música continua a definir personagens, chegando mesmo a servir para as identificar: «este é o Maio o Maio é este» 
canta a personificação deste mês ao entrar em cena. É também ao som de música que surgem as deusas greco-romanas invocadas por Lusitânia, com a particularidade de cantarem e falarem em "ciganês":

Vem estas deosas em dança ao som desta cantiga:

Luz amores de la niña

qué tan linduz ujuz ha

qué tan linduz ujuz ha

ay Diuz quién luz haverá

ay Diuz quién luz cervirá.

Mesmo quando não é executada, a música é várias vezes referida na obra, a modo de comentário à situação representada. Momentos há no desenrolar da intriga em que a inclusão, nos diálogos das personagens, de versos de cantigas populares na época faz ecoar melodias e sentidos na cabeça dos espectadores. É o caso do romance «La bella mal maridada, de las más lindas que yo vi» - um dos grandes êxitos de finais do século xv que perdura durante quase todo o século XVI —, cuja recitação de alguns versos esparsos vai invocando o destino reservado à jovem Lusitânia se chegar a casar com Mercúrio, incapaz para a consumação do casamento, como o próprio confessa:

\author{
Februa Que este galán desposado \\ de los más lindos que yo vi \\ es planeta venerado \\ $[\ldots]$ \\ VÉNUS Las aves a la desposada954 \\ sabes que se monta ahí? \\ Cantarle han por alvorada \\ la bella mal maridada \\ mal gozo viste de ti.
}


As deusas, depois de darem lugar ao célebre quarteto Todo-o-mundo e Ninguém / Dinato e Berzabu «Tornam à sua cantiga, bailando todos ao som dela», como informa a rubrica. Voltarão ainda ao canto para darem fim à farsa.

É assim na quase totalidade do teatro de Gil Vicente. A música cantada vai integrando a ação desenrolada, quase sempre a propósito. No Auto de Mofina Mendes há mesmo uma canção de embalar — «Em este passo chora o menino posto em um berço, as Virtudes cantando o embalam, e o Anjo vai aos Pastores e diz cantando» - que pode ser a mesma entoada pelos Anjos, em circunstâncias idênticas, no Auto da Sebila Cassandra:

Ro ro ro

nuestro Dios y redentor

no lloréis que dais dolor

a la virgen que os parió

ro ro ro.

A propósito de cantigas de embalar é de referir a Comédia de Rubena. Uma Feiticeira, que tem a seu cargo a criação de uma menina recém-nascida abandonada pela mãe, procura uma Ama que a ajude na tarefa. Um dos requisitos para ser admitida é a de ter um repertório variado de cantigas com que possa entreter a menina. O passo é fonte documental que atesta a circulação dessas formas musicais na Península Ibérica:

Feiticeira $\quad$ E que cantigas cantais?
Ama
A criancinha despida
Eu me sam dona Giralda
e também Val-me Lianor
e De pequena matais amor
e Em Paris está don'Alda.

Dime tú señora di

Vámonos dixo mi tío

e Levade-me por el río 
e também Calbi orabi
e Levantei-me um dia
lunes de mañana
e Muliana Muliana
e Nam venhais alegria.

E outras muitas destas tais

que se encontram realmente no teatro de Gil Vicente.

As sonoridades que acompanham a palavra podem por vezes não ser estritamente do domínio musical, produzindo, contudo, uma espécie de contraponto ao discurso.

A cantiga do namorado dirigida à mulher amada chega a ser tema de um longo número da farsa Quem Tem Farelos? Aires Rosado, um escudeiro pobre mas continuamente namorado, como informa a rubrica inicial, prepara-se para ir fazer uma serenata à sua amada. O seu criado e um amigo espreitam-no e ouvem-no a afinar a voz, antes de partir para a rua onde vive a jovem. Trata-se da única música escrita por Gil Vicente que chegou até nós e, diga-se, numa forma muito rudimentar. São sucessões de notas que podem indicar um solfejo ou um ensaio de melodia, mas a verdade é que respeitam a métrica da redondilha e rimam com outros versos:

\section{Canta o Escudeiro:}

Ré mi fá sol lá sol lá.

APARIÇO Vês ali o que t'eu digo.

ESCUDEIRO Que diabo falas tu?

CANTA fá lá mi ré ut.

FALA Nam rosmêes tu comigo

CANTA un día era un día.

APARIÇO Oh Jesu que agastamento.

Escudeiro Dá-me cá esse estromento.

APARIÇO Oh que cousa tam vazia. 
O talento musical de Gil Vicente continua a manifestar-se na cena seguinte, a da serenata propriamente dita, em que o pobre escudeiro se vê interrompido pelo ladrar e ganir dos cães, pelo miar dos gatos e pelo cantar dos galos, que, tal como acontece com as notas musicais, integram os versos e a forma estrófica:

Tange e canta na rua à porta de sua dama Isabel e, em começando a cantar Si dormís doncella, ladram os cães:

Hão hão hão hão.
Escudeiro Apariço mat'esses cães ou vai dá-lhe senhos pães.
Apariço E ele nam tem meo pão.

\section{Canta o Escudeiro:}

Si dormís doncella

despertad y abrid.

\section{$[\ldots]$}

APARIÇO Olhai aquele desvario.

CÃES Hão hão hão hão.

ESCUdEIRO Nam ouço com a cainçada rapaz dá-lhe ũa pedrada ou fart'-os eramá de pão.

Apariço Co as pedras os ajude Deos.

CÃEs Hão hão hão hão.

Uma pedra mais pesada irá fazer ganir os cães:

APARIÇO Toda esta pedra é tam leve tomai lá esta seixada.

CÃES Hãi hãi hãi hãi. 
APARIÇO Perdoai-me vós senhor.

Escudeiro Ora o fizeste pior

ah pesar de minha mãe

Entram em cena os gatos:

Nam há cousa que mais m'agaste

que cães e gatos também.

Gato Miau miau.

ESCUDEIRO Oh que bem,

quant'agora m'aviaste.

Mais tarde cantarão os galos e o escudeiro aproveita a nova interrupção para integrá-la na serenata que faz:

GAlos Cacaracá cacaracá.

346

EscudeIRo Mea noite deve ser.

APARIÇO Já fora rezão comer

pois os galos cantam já.

Escudeiro cantando:

Cantan los gallos

yo no me duermo

ni tengo sueño.

Não é caso único em que a musicalidade dos versos de Gil Vicente se compõe com recurso a elementos paramusicais. Na Tragicomédia Nau de Amores, o frade doudo talvez imite uma campainha ao entrar em cena ("Frade doudo: Tingue tingue tingue tingue») e na Tragicomédia Triunfo do Inverno soa por várias vezes um apito que, também ele, «toca» em verso, durante uma tempestade marítima:

ApITO Pii pi pi pi pi.

GRIGÓRIO Tanto monta assoviar 
coma aquilo que sé 'li.

(Tragicomédia do Inverno e Verão)

O universo musical de Gil Vicente pode ser recuperado muitas vezes através das notações musicais que acompanham, em diversos cancioneiros ibéricos, as cantigas, vilancetes e romances que Gil Vicente escreveu ou utilizou ${ }^{2}$.

Seja exclusivamente instrumental, seja cantada ou bailada, no elenco das peças de Gil Vicente a música ocupa um lugar de protagonista.

2 Manuel Morais identificou já as fontes musicais do teatro de Gil Vicente em "Música para o teatro de Gil Vicente (Fl. 1502-1536)", em Gil Vicente 500 Anos depois, vol. II (org. Maria João Brilhante, José Camões, Helena Reis Silva, Cristina Almeida Ribeiro), Lisboa, INCM, 2003, pp. 45-115, tendo também editado, com os Segréis de Lisboa, o CD Música para o Teatro de Gil Vicente 1502-1536 (Potugaler, 2003) com algumas dessas composições. 